\title{
O passado é o prólogo
}

\author{
Alisson F. Barbieri \\ Ricardo Ojima**
}

\section{População e desenvolvimento: a abordagem}

Nos últimos dois anos, verifica-se a volta, de forma acentuada, do debate em torno das relações entre população e desenvolvimento. Os artigos da Revista Brasileira de Estudos de População (Rebep) têm evidenciado esta tendência, assim como o Encontro da Associação Brasileira de Estudos Populacionais (Abep), que acontecerá no segundo semestre de 2010, cujo tema central é a relação entre população e desenvolvimento.

Conforme descrito no sítio da Abep (www.abep.org.br), um objetivo da escolha deste tema é discutir e explicitar, para a comunidade acadêmica, a contribuição da demografia para os desafios brasileiros imediatos e futuros, em particular diante das repercussões do novo ciclo de crescimento/desenvolvimento econômico brasileiro sobre as migrações e o meio ambiente.

O Encontro da Abep é, de certa forma, o ápice de um debate iniciado pela demografia brasileira nos últimos anos em vários fóruns. Por exemplo, em agosto de 2009, Belo Horizonte hospedou o evento "Brasil 15 anos após a Conferência do Cairo", em que a comunidade abepiana refletiu sobre os avanços e desafios para a pesquisa em população, passados 15 anos da Conferência do Cairo. Foram ainda discutidos os desafios futuros e as perspectivas para as políticas públicas e sociais, tendo em vista as mudanças demográficas recentes. O evento foi também uma oportunidade para que os grupos de trabalho da Abep pudessem se reunir e abordar temas relacionados à temática central do evento em questão, bem como planejar os debates futuros. Esta é uma discussão complexa, uma vez que a análise interdisciplinar entre os componentes da dinâmica demográfica e as questões ambientais ainda constitui um campo em construção na demografia brasileira.

Com efeito, é a partir de esforços conjuntos como este que se iniciam reflexões promissoras e se constroem redes de discussão, que viabilizarão a formação de novos espaços e de uma nova forma de se pensar a relação população-ambiente. Assumimos, sempre, que a questão ambiental é indissociável do debate sobre dinâmica populacional e desenvolvimento. Isso é particularmente relevante, quando se nota que o Brasil tem passado por importantes transições nas últimas décadas - a transição demográfica, a transição epidemiológica, a (consolidação) da transição urbana e o seu modo de vida associado -, que definem e são definidas por uma relação específica com o ambiente.

\footnotetext{
* Professor do Departamento de Demografia e pesquisador do Centro de Desenvolvimento e Planejamento Regional (Cedeplar), Universidade Federal de Minas Gerais (UFMG); coordenador do Grupo de Trabalho "População, Espaço e Ambiente", da Associação Brasileira de Estudos da População (Abep).

${ }_{\star *}$ Pesquisador da Fundação João Pinheiro (FJP/MG); pesquisador colaborador do Núcleo de Estudos de População (Nepo/Unicamp) e do Departamento de Demografia (DD/IFCH/Unicamp); co-coordenador do Grupo de Trabalho "População, Espaço e Ambiente", da Associação Brasileira de Estudos da População (Abep).
} 
Um exemplo deste esforço conjunto é o trabalho apresentado por Hill e Queiroz, nesse número da revista. Os autores explicitamente incorporam a migração nas estimativas de subregistro de óbitos, tendo em vista que este componente não pode ser mantido, ingenuamente, fixo ao longo do tempo. Outro exemplo é o estudo de Brito e colaboradores, comparando métodos distintos para as estimativas de projeções de população em pequenas áreas e, assim, fornecendo instrumental para que muitas análises prospectivas sobre condições tais como moradia e saúde das populações sejam projetadas e planejadas. Um exercício empírico interessante e interdisciplinar também é o de Godoy e Paiva, os quais reconstroem a estrutura ocupacional de Minas Gerais no século XIX, lançando luz às possibilidades de trabalhar dados (aparentemente) incompletos. Finalmente, com o objetivo de incrementar e aumentar a utilização e o entendimento de aspectos relacionados a um método de formação de grupamentos muito utilizado entre demógrafos - o Grade of Membership (GoM) -, Guedes e colaboradores propuseram um procedimento que, seguido de forma sistemática, auxilia na identificação de um modelo estável e que possa representar, fidedignamente, o fenômeno demográfico que se deseja retratar.

Neste número, o tema população e desenvolvimento é estudado dentro de várias perspectivas, sendo tratado de forma mais explícita por Oliveira; Cunha e Jakob; e Alves e colaboradores. Os trabalhos de Abreu e colaboradoras, Verona e colaboradores, bem como a revisão de literatura de Lima, também enfocam a inter-relação entre população e desenvolvimento, a qual é expressa por meio da identificação de fatores de risco associados com a mortalidade. Já o ponto de vista de Miranda-Ribeiro e Potter e a resenha de Correa abordam a fecundidade na adolescência e a questão das desvantagens da maternidade nessas idades, tendo por base os desafios teóricos e evidências empíricas recentes. Sob outro ângulo, o trabalho de Vieira Junior e Barroso evidencia, em uma perspectiva da demografia histórica, os movimentos de portugueses na Amazônia no século XIX, tangenciando sua importância na conformação do povo brasileiro. Na seção notas de pesquisa, as instituições de longa permanência para idosos são contempladas por Kanso e Camarano, tema da mais extrema importância, tendo em vista a transição demográfica e o crescente aumento do número e proporção dos idosos no Brasil.

\section{A perda e o reencontro}

E é nesse momento em que a relação população-desenvolvimento-ambiente assume uma centralidade cada vez maior na demografia brasileira (exemplificada neste volume pela resenha de Sathler e Reis sobre o livro de Hogan e Marandola - População e mudança climática: dimensões humanas das mudanças ambientais globais) que sentimos a perda de um de nossos mais relevantes e estimados colegas, o professor Daniel Hogan. Nascido nos Estados Unidos, Daniel graduou-se em 1964 em Letras, pela Universidade Le Moyne College, fez mestrado em sociologia do desenvolvimento (1968) e doutorado em sociologia e demografia (1974), ambos pela Universidade Cornell. Ele foi pró-reitor de Pós-Graduação da Unicamp de 2002 a 2005 e possuía vasta produção científica na área de população e meio ambiente. Atuou junto aos Núcleos de Estudos da População (Nepo) e de Estudos e Pesquisas Ambientais (Nepam), centros de pesquisa que ajudou a fundar. Recentemente dedicava-se à pesquisa das dimensões humanas das mudanças ambientais globais e coordenava projetos e redes de pesquisa na área, abrindo novos campos de estudo para o cenário brasileiro.

Foi com a capacidade de articulação e de diálogo, que tanto o caracterizavam, que ficou marcada sua atuação enquanto presidente da Abep, nos períodos 1995-1996 e 1997-1998. Dentro do GT de População, Espaço e Ambiente, foi um incentivador e orientador, buscando sempre atrair novas ideias e pessoas para oxigenar os debates, convencido da necessidade de enfrentar os desafios de campos de conhecimento ainda pouco consolidados. Neste aspecto, Daniel foi um dos cientistas que formaram o primeiro Comitê em População e Meio Ambiente da IUSSP (entre 1990 e 1994), contribuindo decisivamente não só para a consolidação do tema "População e Ambiente" como área relevante de estudo na demografia, mas também 
para a formação de uma rede mundial de pesquisadores especializados - o Population and Environment Research Network (PERN). Daniel teve papel de destaque no processo de inserção de pesquisadores brasileiros em importantes fóruns científicos mundiais sobre População, Desenvolvimento e Ambiente. Enfim, Daniel Hogan foi de grande importância para o debate de questões ambientais e demográficas, e deixará um vazio enorme nos corredores do Hotel Glória (em Caxambu), local de realização dos encontros da Abep, não apenas pela forma tranquila com que transmitia suas ideias, mas também pela maneira respeitosa e cordial com que tratava todas as pessoas, sobretudo seus alunos.

O que somos e o que fazemos é, em grande parte, fruto do que aprendemos com as pessoas que passam por nossas vidas. Amigos, mestres, professores, amores, não importa o papel que representaram, é a lembrança do aprendizado que deixaram que os tornam imortais. "Aqueles que passam por nós não vão sós, levam um pouco de nós e deixam um pouco de si" (Antoine de Saint-Exupery). Se acreditarmos nisso, o passado e o futuro, a morte e a vida se misturam e se tornam parte de algo permanente - nossa consciência, nossa razão e os exemplos que nós mesmos deixaremos. What's past is prologue (W. Shakespeare, The tempest, Act II, Scene 1). 